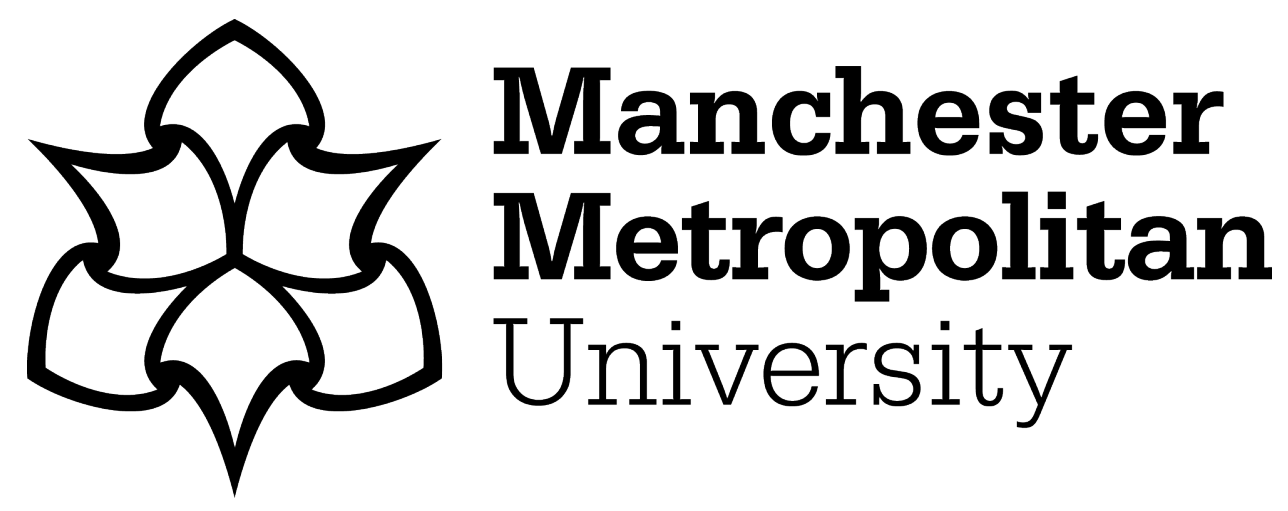

Ngo, Huyen and Walton, Geoff (2016) Examining the Practice of Information Literacy Teaching and Learning in Vietnamese Upper Secondary Schools. Education for Information, 32 (3). pp. 291-303. ISSN 0167-8329

Downloaded from: https://e-space.mmu.ac.uk/622273/

Version: Accepted Version

Publisher: IOS Press

DOI: https://doi.org/10.3233/EFI-160978

Please cite the published version 


\title{
EXAMINING THE PRACTICE OF INFORMATION LITERACY TEACHING AND LEARNING IN VIETNAMESE UPPER SECONDARY SCHOOLS
}

\begin{abstract}
Information literacy (IL) research has been hitherto dominated by the USA, Australia and the UK [22]. Vietnam, however, remains under-represented and there is no IL work in upper secondary schools in the country to date. This paper, which is part of an ongoing $\mathrm{PhD}$ research, presents preliminary findings of the study to understand IL level of students as well as explore the practice of teaching and learning IL. The research proposes a model to help develop IL for schools in Vietnam based on Standards for the $21^{\text {st }}$-Century Learner introduced by the American Association of School Librarians (AASL), and driven by study programme as well as current educational initiatives in the country. The research employs a mixed methods approach to assist the researcher in providing a rich picture of the practice of IL in the Vietnamese educational context. The preliminary findings indicate that there are some aspects of students' IL level that need to be improved. The findings also show that teaching IL is not the focus of the school although they acknowledge its importance to pupils. It is clear that more work needs to be done to strength students' capabilities.
\end{abstract}

Keywords: Information literacy, secondary schools, Vietnam, Standards for the $21^{\text {st }}$-Century Learner 


\section{Introduction}

We cannot deny the important role of IL as it helps us survive in an ever-changing information environment [12]. The emergence of IL as an issue at a global level $[30,41,42]$ indicates its importance. IL has been identified as essential in the $21^{\text {st }}$ century $[8,14,20,32,42]$. According to Walton and Cleland [13], becoming information literate occurs in a wider social context; and IL comprises three spheres which are finding, evaluating and using information and each sphere triggers its own set of behavioural, cognitive, metacognitive, and affective states.

The term IL has become increasingly fashionable in recent years [38]; and there is a great body of research from both practitioners and academics around the world such as USA, Australia, UK, Africa and some countries in the Far East [22]. However, there is lack of IL studies in the Vietnamese context. Therefore, this research will address the gap by investigating the practice of IL teaching and learning in Vietnamese upper secondary schools. A study was conducted in a nonpublic upper secondary school in Vietnam. This paper presents preliminary findings of the study to understand Vietnamese upper secondary students' IL level and explore the practice of IL teaching and learning in the school.

\section{Vietnamese educational context}

The Vietnamese educational system is under the management of the Ministry of Education and Training (MOET). In Vietnam, upper secondary school includes 
grade 10 through 12 . Also, high schools are divided into two types: public and nonpublic schools. Specifically, public schools are established and managed by the state agencies. The state funds infrastructure construction and recurrent expenditure. Non-public schools are established and managed by social organisations, social-professional organisations, economic organisations and individuals under the permission of the state agencies. Funding for infrastructure construction and recurrent expenditure is from the organisations themselves or individuals, not from the state [28].

Regarding the goals of upper secondary education, students need to develop physical and mental powers harmoniously based on maintaining, strengthening and determining the virtue and competencies that are taking shape from lower secondary education level. Additionally, students should have career-oriented knowledge and skills in accordance with their interests. At the same time, developing personal capacities is needed to help them define development direction in the future such as going into further education and entering working life [29].

Teaching and learning foreign languages, especially the English Language, is the focus of the Vietnamese educational system in the 'new period' (2011-2020). This aims to train those who will be capable of working in a socialist-oriented market economy [44]. This aim is demonstrated through a series of recent educational projects such as "Teaching and learning foreign languages in the national education 
system 2008-2020" [43], "Educational development strategy 2011-2020" [44] and "Building a learning society 2012-2020" [45].

Furthermore, Vietnamese secondary schools attempt to replace the traditional delivery mode of transmission by self-discovery, discussion and self-explanation that allow students to expand their knowledge and improve research skills.

This research will investigate upper secondary students' capacities which need to be improved as well as whether there are any issues in IL teaching and learning. As a result, this project will assist Vietnamese upper secondary schools in developing IL teaching activities.

\section{Literature review}

IL has many definitions and its own cannon of research output and theoretical perspectives $[4,25,34]$. However, at present, there is no common definition of IL that is agreed by all research communities in the world [12]. IL could be considered a 'multi-faceted' concept [35]. This results to IL being interpreted in many different manners. Various authors have defined IL differently as Hepworth and Walton [23, p. 29] showed that IL is "a multidimensional phenomenon that can be thought about from different perspectives, including individual, social, cultural and global". Hepworth [24] also highlighted two main approaches to IL. The first one emphasises the skills-based approach. The second one concentrates on individuals' experiences with information. 
A number of IL models have been developed for compulsory education (pre-school to 18 years of age - the short-hand used in the United States and some other countries as K-12 education). In K-12 environment, the Big Six Skills Approach [19] was developed to emphasise the significance of IL skills in solving problems. The American Association of School Librarians and the Association for Educational Communications and Technology (AASL \& AECT) introduced the Nine Information Literacy Standards for Student Learning [6] to afford instructions for defining an information literate student. In 2007, four Standards for the 21stCentury Learner [5] were developed as a new set of standards grounded on the Nine Information Literacy Standards for Student Learning.

In higher education settings, various IL models were also developed. Society of College, National \& University Libraries (SCONUL) [39] devised a 'seven pillars' model used to promote the quality of university and national libraries' services across the United Kingdom and Ireland. The ACRL standards [7] (USA) offer a model for measuring the information literate person. The ANZIIL framework [2] (Australia and New Zealand) follows the ACRL model and contains one extra standard to the original [35]. This model reflects on the relationship between IL and learning in a more detailed fashion. In addition, Bruce and Edwards have also criticised this existing work on IL and offer a new approach to researching and defining IL. A relational model for IL was suggested as an alternative to what they regard as behavioural approaches which do not encourage deep learning [10]. 
With regard to IL assessment, measuring students' IL level is essential in understanding the effectiveness of the current IL programmes as well as in informing suggestions that support and enhance students' IL level [48]. Therefore, Warmkessel [26] introduces an assessment cycle which shows that it is necessary to identify what to measure, how to measure, and how to use the results when conducting an IL assessment. There are many ways to measure IL level and each method has its own strengths and weaknesses $[3,26]$ such as multiple choice questionnaires, observation, portfolios, essay, bibliography analysis, quiz/test, selfassessment, final grades, and simulation. Using multiple choice questionnaires to assess students' IL is considered the most popular method [3]. An example of using this approach can be found in the work undertaken by Chang et al. $[47,48]$ and Chu [36]. Some other techniques were also employed to measure students' IL at all levels, for example, portfolios [11], essay [15], performance and self-assessment [21], fixed-choice tests, performance assessment and rubrics [27], online quizzes [33], and interviews [37].

\section{Conceptual framework}

Four Standards for the 21st-Century Learner introduced by the AASL are used as the IL conceptual framework. However, an expanded version of AASL's model, as illustrated in Figure 1 (Fig. 1), is needed for the Vietnamese educational context. AASL's model is based on educational environment in United States where English is used in the national education system. Furthermore, English is one of the 
most widely used languages in the world $[9,16]$. Many information resources are produced and published in English. Research conducted by W3Techs indicated that English was used as the content language of approximately $55.6 \%$ of the most visited websites in the world. Meanwhile, the most visited websites that used Vietnamese accounted for less than $0.5 \%$ [46]. Consequently, Vietnamese people in general and students in particular who can use English gain an advantage in learning and communication as well as in accessing a great wealth of information resources. Peyina [18] and Johnson [31] assume that language use affects an individual's IL. In Vietnam, an individual will encounter many challenges in engaging with information in particular and becoming information literate in general if they do not use foreign language. In addition, being proficient in English is one of the essential learning outcomes of the study programme. From the previous discussion, it can be said that foreign language use should be considered an additional standard to assess students' IL learning.

\section{Methodology}

This section presents the development of the data collection techniques, sample selection and data collection process.

\subsection{Data collection technique development}

Questionnaire: A paper survey was administered to upper secondary students in a non-public school in Vietnam to assess pupils' IL level. The questionnaire was designed to be easy for students to complete, with the use of closed questions, no 
written responses required. There are many benefits in using fixed-choice questions to measure students' IL level such as they are easy, quick and inexpensive to score, generate numerical data and highly reliable data [27]. The data from the returned questionnaires was analysed using SPSS.

The survey contained 35 questions and was split into three sections as follows:

Section A - About you: included 5 questions that obtained demographic data of the study population.

Section B - Awareness and self-rating: consisted of 6 questions with the aim of identifying students' awareness about the concept of IL as well as their IL level.

Section C - Your information literacy: a set of 23 multiple choice questions were used to investigate students' IL level in terms of developing search strategies, evaluating information sources, using information ethically, and using foreign language to engage with information effectively. Students scored 1 point for each correct answer and each question had only one correct answer. The researcher did not measure all five standards of the model explained above (Fig. 1) due to limitations of budget, human resources and time. The questionnaire used indicators of standard 1 and 5 which are "Inquire, think critically, and gain knowledge" and "Use language to engage with information effectively" out of five standards to measure four IL areas as described above.

The questionnaire was based on the $12^{\text {th }}$ grade version of IL competency level assessment toolkit of high schools in USA known as TRAILS - Tool for Real-time 
Assessment of Information Literacy Skills, a project which was devised at Kent State University Libraries [17]. TRAILS was chosen because it is based on the AASL Standards for the $21^{\text {st }}$ Century Learner. Using existing questions, in this case is using TRAILS, helps to increase reliability and validity of the measure tool because it has been rigorously piloted as recommended by Bryman [1]. However, the questions were changed to suit the Vietnamese context. Modifications to the questions were based on suggestions made by a group of professionals, including an expert in information science, an upper secondary school teacher, and a school librarian. The questionnaire was sent to this group to seek their feedback before delivering to students.

Interview questions: Three semi-structured interviews with students were undertaken to understand reasons behind different results of the test as well as investigate what and how students had been taught in IL. Content analysis was used as a technique to analyse qualitative data in this research [1].

Official documents: A document content analysis was conducted to triangulate the findings of the student interviews. The document analysis involved various documents such as library reports, library statistics, student handbook, guidelines, study program, teaching resources, school website, and library plans.

\subsection{Participants}


The survey involved upper secondary students $(n=17)$ from a non-public upper secondary school in Vietnam. The participants were aged from 15 to 18 . The librarian was used as a key informant to invite students to participate in the research. The follow-up interviews involved 3 students who sought different IL test scores including lowest score (39), average (61) and highest (87) score.

\section{Results}

This section presents significant findings of the study.

\subsection{IL test scores}

The raw scores were transformed into percentages because the number of questions for four IL testing areas was not equal. The three groups of percentage scores including less than or equal to $30 \%(\leq 30)$, more than $30 \%$ and less than $70 \%$, and more than or equal to $70 \%(\geq 70)$ were then recoded into values such as low, average, and high respectively. The IL scores of the study population ranged from 39 to 87 out of a maximum score of 100 , with a mean score at 59.41/100. It was found that, $70.6 \%$ of students achieved average scores and more than one-fourth (29.4\%) of them reached high scores, no students obtained low scores (Fig. 2). From the interviews, it can be seen that, the difference between cases in their experiences in learning IL outside school and awareness of opportunities to develop IL in school might cause different results in IL scores. Students with a better performance often attend outside school activities such as academic clubs, events and discussions on social issues than students who had lower scores. 
Regarding the percentage scores for each aspect of IL, it was found that, out of the four IL testing areas, the best scored aspect was using foreign language to engage with information effectively (mean score: 69.53). Meanwhile, the lowest scores were for evaluating information sources (mean score: 37.12 ). At the same time, the performing mean scores of developing search strategies and using information ethically were 61.18 and 55.88 respectively (Table 1). The results indicate that students were good at searching information but weak at evaluating it.

6.2. Comparison of IL levels between female and male students

In general, female students were found to score higher than male students (mean score: 67.00 vs. 52.67). Independent sample t-test was employed to explore the relationship between males and females in IL. It can be assumed that there was a statistical significant difference in overall IL scores between girls and boys $(t=$ 2.468, $\mathrm{df}=15, \mathrm{p}=0.026)($ Table 2$)$.

\subsection{Self-rating of IL level}

Students were asked to rate their IL level in terms of being or not being information literate. It was found that, $76.47 \%$ rated their IL level at high level. Meanwhile, just $17.65 \%$ ranked their IL level at average level and 5.88\% thought their IL level was low (Fig. 3).

6.4. Correlation of IL scores and self-rating 
Spearman Correlation Coefficient was used to examine whether there is a relationship that exists between self-rating and IL scores. In broad terms it appears that there was a linear relationship between IL scores and self-rating, with $r>0$. However, this relationship is weak because $r<0.1$ (Table 3).

\subsection{Correlation of hearing/reading about IL and IL scores}

Chi-square test was used to investigate the relationship between hearing/reading about IL prior to this study and students' IL level. The results indicate that, the proportion of the sample hearing or reading about the term was $17.7 \%$ in comparison with $82.3 \%$ of those who had not heard or read about the term. It was found that there was no relationship between hearing/reading about IL and IL scores $\left(X^{2}=8.972^{a}, d f=8, p=0.345\right)$. In other words, hearing/reading about IL did not affect individuals' IL scores (Table 4).

\subsection{IL teaching}

Interview data and documents from the school provided an overall picture of teaching IL in the institution. It was found that developing students to be lifelong learners was integrated in the mission of the school. However, there was still no formal IL programmes in the institution. It is argued that some individual instructions from teachers, when students conducted projects, may help them to develop IL. According to pupils, there were three main reasons leading to no IL initiatives in the school, including: 
- The concept of IL not matching known models, even amongst those who are educators.

- The weakness of Vietnamese' perception of IL.

- The lack of opportunities to use IL because of the transmission approach in teaching and an overloaded study programme enforced by the Ministry of Education and Training.

\section{Discussion}

It can be seen that students had better performance at earlier stages of the process of engaging with information. This finding is similar to the results of an IL assessment in Singapore that shows that students have higher level of the earlier stages of the information behaviour [48]. Adams [37] also indicates that students had problems in evaluating scientific claims made in media sources. This suggests that the institution should pay more attention in improving students' capacity in evaluating information sources. However, improving this skill requires many efforts from the institution, teachers, librarians and pupils. The institution needs to show to students the importance of information evaluation. At the same time, they should establish guidelines and assessment tools in order to help students enhance their evaluation capacity. Furthermore, it was found that male students had worse IL performance than female students. This result reinforces the findings of researches conducted by Chu [36], Chang et al. [47] and Liu and Sun [40] which explores the difference between females and males in primary -5 students in Hong Kong and Singapore, and science and engineering undergraduates in China 
respectively in IL skills. Therefore, the institution should make more effort to improve male students' IL level. The collaboration between the institution, teachers, librarians and females should be considered a solution to help males improve their IL.

The findings show that students self-rated their IL level higher than their real level. In other words, pupils were confident in their own IL level and thought positively of themselves. Gross and Latham [21] and Price et al. [33] also indicate that students were overconfident in their IL level. This suggests that it is necessary to provide students an insight on the concept of IL. Furthermore, the institution, teachers and librarians should show their students what they need to improve in IL.

The results indicate that although students had the same viewpoint on the role of IL, experiences in learning IL outside school and awareness of opportunities to develop IL in school might cause different results in IL scores. Although developing students to be lifelong learners was integrated in the mission of the school, the institution did not have any clear instructions related to IL. Therefore, this suggests that an IL programme should be run for students.

\section{Conclusion}

This study has found that generally upper secondary students of the institution had better IL performance in searching information (using English and Vietnamese) than other skills, especially information evaluation. It was also shown that females 
were good at IL than males. In addition, an investigation of IL test scores and other aspects such as IL self-assessment and hearing/reading about IL shows the following: 1) there was no relationship between IL scores and self-rating; 2) hearing/reading about IL did not affect individuals' IL scores. Furthermore, it seems participation in academic and social activities outside school helps students gain more experiences on IL than those who do not take part in such activities. This may be the result of the absence of IL programmes in the school. The reasons for the absence of IL interventions comprise lack of understanding of IL, traditional teaching method and an overloaded study programme.

The results indicate that more work needs to be done to strength students' capabilities. It can be seen that information source evaluation needs more attention than other skills. Furthermore, the school needs to pay attention to teaching IL in the future in order to support students' learning more effectively. Teaching IL also requires the attention of MOET. MOET should have appropriate policies to guide schools in teaching IL. Also, it is necessary to improve school managers' understanding of the concept and the importance of IL. Additionally, the compilation of the supporting document and the improvement of teachers' capacity in IL teaching also need to be considered. Finally, the school should recognise the valuable contribution librarians make in teaching IL.

This study is the first attempt to assess IL level of Vietnamese upper secondary students and investigate the practice of IL teaching and learning. Only one school 
was involved in the study and 17 students took part in the survey. It can be seen that the number of participants was low. Therefore, it is suggested that assessment of IL level of Vietnamese upper secondary students should be conducted using a wider sample in order to provide a richer picture of their IL. Furthermore, it is recommended that future studies are based on the recommendations of the research presented here.

\section{Acknowledgements}

The project is supported by the Ministry of Education and Training - Vietnam. Therefore, the researchers would like to express a special gratitude towards the Ministry of Education and Training - Vietnam for awarding us such an opportunity to conduct the research.

\section{References}

[1] A. Bryman, Social research methods, (4th ed). Oxford: Oxford University Press, 2012.

[2] A. Bundy, eds, Australian and New Zealand information literacy framework: principles, standards and practice. Adelaide: Australian and New Zealand Institute for Information Literacy, 2004.

[3] A. Walsh, Information literacy assessment: Where do we start?, Journal of Librarianship and Information Science 41 (1) (2009), 19-28. 
[4] A. Whitworth, Nurturing information landscapes: networks, information literacy and the need for a critical phenomenography, 9th International Conference on Networked Learning, 7-9 April 2014, Edinburgh.

[5] AASL, AASL standards for the $21^{\text {st }}$ century learner. Chicago: American Library Association, 2007.

[6] AASL, Information power: Building partnerships for learning. Chicago: American Library Association, 1998.

[7] ACRL, Information literacy competency standards for higher education. Chicago: American Library Association, 2000. Available online at: http://www.ala.org/acrl/standards/informationliteracycompetency.

[8] ALA, American Library Association Presidential Committee on Information Literacy: Final report. Chicago: American Library Association, 1989. Available online at: http://www.ala.org/acrl/publications/whitepapers/presidential.

[9] British Library, Minority ethnic English, 2015. Available online at: http://www.bl.uk/learning/langlit/sounds/case-studies/minority-ethnic/.

[10] C. Bruce and S. Edwards, Six frames for information literacy education: a conceptual framworkork for interpreting the relationships between theory and practice, Italics 5 (1) (2006), 1-18. Available online at: http://www98.griffith.edu.au/dspace/bitstream/handle/10072/14028/36236.p $\mathrm{df}$ ? sequence $=1$. 
[11] D. Scharf, N. Elliot, H. A. Huey, V. Briller and K. Joshi, Direct assessment of information literacy using writing portfolios, The Journal of Academic Librarianship 33 (4) (2007), 462-477.

[12] F. Schubert et al., Information literacy skills of secondary school students in Singapore, Aslib Journal of Information Management 66 (1) (2014), 54-76.

[13] G. Walton and J. Cleland, Becoming an independent learner, in: Rethinking information literacy: a practical framework for supporting learning, J. Secker and E. Coonan, ed., Facet, London, 2013, pp. 13-26.

[14] H. Rader, Information literacy - A revolution in the library, $R Q \mathbf{3 1}$ (1) (1991), 25-29.

[15] J. Nutefall, Paper trail: One method of information literacy assessment, Research Strategies 20 (1) (2004), 89-98.

[16] J. Pak, Is English or Mandarin the language of the future?, 2012. Available online at: http://www.bbc.co.uk/news/magazine-17105569.

[17] Kent State University Libraries, TRAILS - Tool for Real-time Assessment of Information Literacy Skills, 2015. Available online at: http://www.trails9.org/.

[18] L. Peyina, Information literacy barriers: language use and social structure, Library Hi Tech 28 (4) (2010), 548-568.

[19] M.B. Eisenberg and R.E. Berkowitz, Information problem-solving: The Big Six Skills approach to library \& information skills instruction. Norwood: Ablex Publishing Corporation, 1990. 
[20] M. B. Eisenberg, C. A. Lowe and K. L. Spitzer, Information literacy: essential skills for the information age. Westport, Conn: Libraries Unlimited, 2004.

[21] M. Gross, and D. Latham, Attaining information literacy: An investigation of the relationship between skill level, self-estimates of skill, and library anxiety, Library and Information Science Research 29 (3) (2007), 332-353.

[22] M. Hepworth and G. Walton, Developing people's information capabilities: fostering information literacy in educational, workplace and community contexts. Bingley, United Kingdom: Emerald, 2013.

[23] M. Hepworth and G. Walton, Teaching information literacy for inquirybased learning. Oxford: Chandos, 2009.

[24] M. Hepworth, Approaches to providing information literacy training in higher education: challenges for librarians, New Review of Academic Librarianship 6 (2000), 21-34.

[25] M. Leaning, Issues in information and media literacy. Santa Rosa: Informing Science Institute, 2009.

[26] M. M. Warmkessel, Information literacy assessment, Public Services Quarterly 3 (1-2) (2007), 243-250.

[27] M. Oakleaf, Dangers and opportunities: A conceptual map of information literacy assessment approaches, Portal: Libraries and the Academy 8 (3) (2008), 233-253.

[28] MOET, Decision No. 07/2007/QĐ-BGDĐT: Decision of the Minister of Education and Training - Regulations for junior high schools, senior high 
schools and multi-level high schools, Hanoi, 2007. Available online at: http://www.moj.gov.vn/vbpq/Lists/Vn\%20bn\%20php\%20lut/View_Detail.as px?ItemID $=13446$.

[29] MOET, Secondary education program, 2014. Available online at: http://dhsptn.edu.vn/uploads/news/2014_02/chuong-trinh-giao-duc-phothong.pdf.

[30] N. Graham, Conference Report from the International Conference on Media and Information Literacy for Knowledge Societies, Journal of Information Literacy 6 (2) (2012), 138-139.

[31] N. Johnson, Understanding the information literacy experiences of EFL (English as a foreign language) student, Ph.D. Thesis, Queensland University of Technology, 2014.

[32] P. Breivik, 21st century learning and information literacy. Philadelphia: Taylor \& Francis Inc, 2005.

[33] R. Price, K. Becker, L. Clark and S. Collins, Embedding information literacy in a first-year business undergraduate course, Studies in Higher Education 36 (6) (2011), 705-718.

[34] S. Andretta, Change and challenge: information literacy for the 21st century. Adelaide, Auslib Press, 2007.

[35] S. Andretta, Information literacy: a practitioner's guide. Oxford, Chandos, 2005.

[36] S. K. W. Chu, Assessing information literacy: A case study of primary 5 students in Hong Kong, School Library Research 5 (2012), 1-24. 
[37] S. T. Adams, Critiquing claims about global warming from the world wide web: A comparison of high school students and specialists, Bulletin of Science, Technology and Society 19 (1999), 539-543.

[38] S. Thornton, Pedagogy, politics and information literacy, Politics 28 (1) (2008), 50-56.

[39] SCONUL, The SCONUL Seven Pillars of Information Literacy: Core model for higher education, 2011. Available online at: http://www.sconul.ac.uk/sites/default/files/documents/coremodel.pdf.

[40] T. Liu and H. Sun, Gender differences on information literacy of science and engineering undergraduates, I.J.Modern Education and Computer Science 2 (2012), 23-30.

[41] UNESCO, Beacons of the Information Society - The Alexandria Proclamation on Information Literacy and Lifelong Learning, 2006. Available online at: http://portal.unesco.org/ci/en/ev.phpURL_ID=20891\&URL_DO=DO_TOPI C\&URL_SECTION=201.html.

[42] UNESCO, The Prague declaration: Toward an information literate society, Teacher Librarian 31 (3) (2004), 53.

[43] Vietnamese Government, Decision No. 1400/QĐ-TTg about approving the scheme "Teaching and learning foreign languages in the national education system 2008-2020", 2008.

[44] Vietnamese Government, Decision No. 711/QĐ-TTg about approving "Educational Development Strategy 2011-2020", 2012. 
[45] Vietnamese Government, Decision No. 89/QĐ-TTg about approving the scheme "Building a learning society 2012-2020", 2012.

[46] W3Techs, Usage of content languages for websites, 2015. Available online at: http://w3techs.com/technologies/overview/content_language/all.

[47] Y. Chang, S. Foo and S. Majid, Assessing IL skills of primary - 5 students in Singapore, in: Information literacy: Lifelong learning and digital citizenship in the 21st century, S. Kurbanoglu, S. Spiranec, E. Grassian, D. Mizrachi and R. Catts, ed., Springer, London, 2014, pp. 531-539.

[48] Y. Chang, X. Zhang, I. A. Mokhtar, S. Foo, S. Majid, B. Luyt, and Y. Theng, Assessing students' information literacy skills in two secondary schools in Singapore, Journal of Information Literacy 6 (2) (2012), 19-34. 
Tables

Table 1

Scores for four testing areas

\begin{tabular}{lccc}
\hline Testing areas & Mean & Minimum & Maximum \\
& $(\%)$ & $(\%)$ & $(\%)$ \\
\hline Evaluating information sources & 37.12 & 0 & 67 \\
Using information ethically & 55.88 & 25 & 100 \\
Developing search strategies & 61.18 & 30 & 100 \\
Using foreign language to engage with & 69.53 & 17 & 100 \\
information effectively & & &
\end{tabular}


Table 2

Comparison of IL scores between females and males

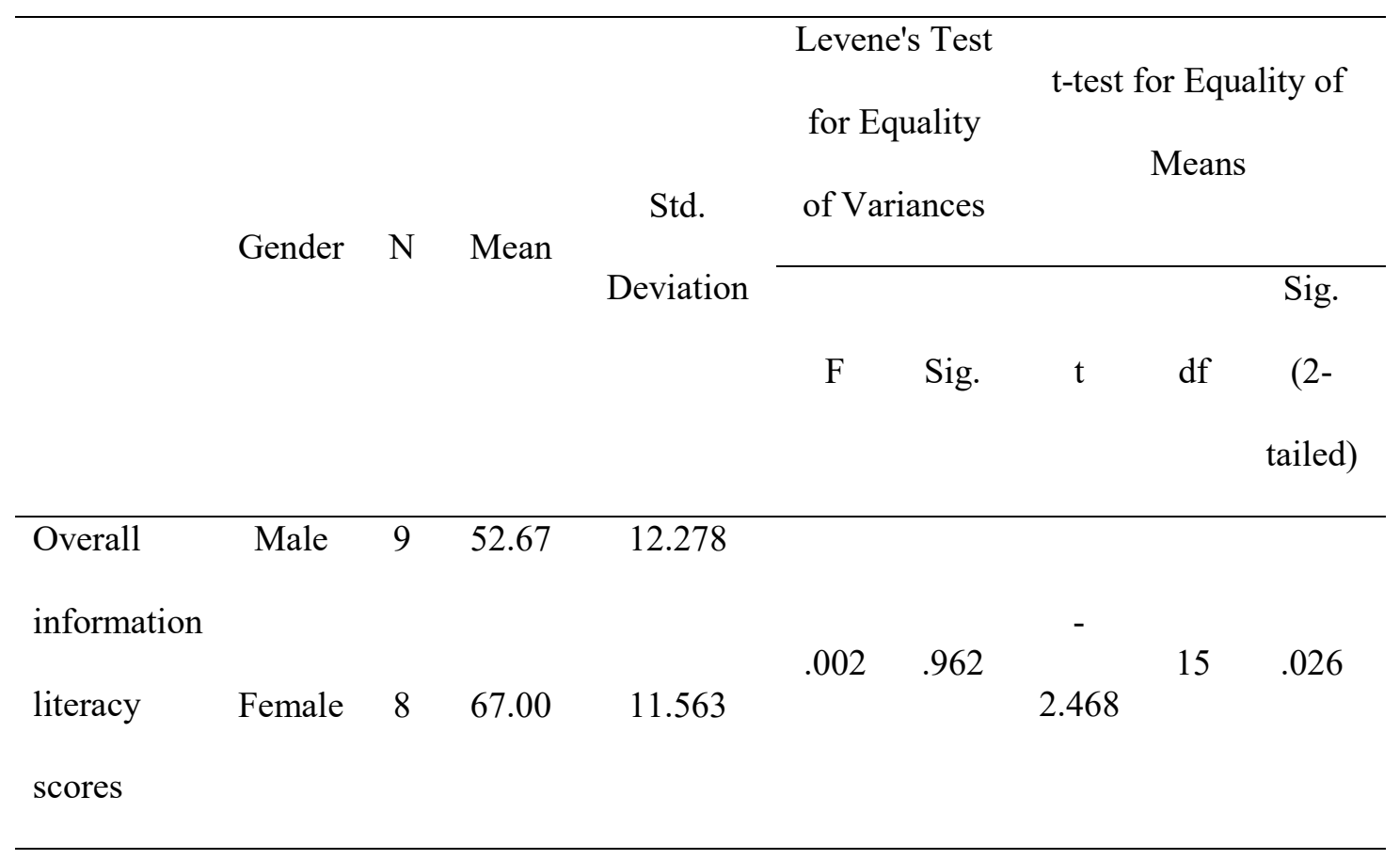


Table 3

Correlation of IL scores and self-rating

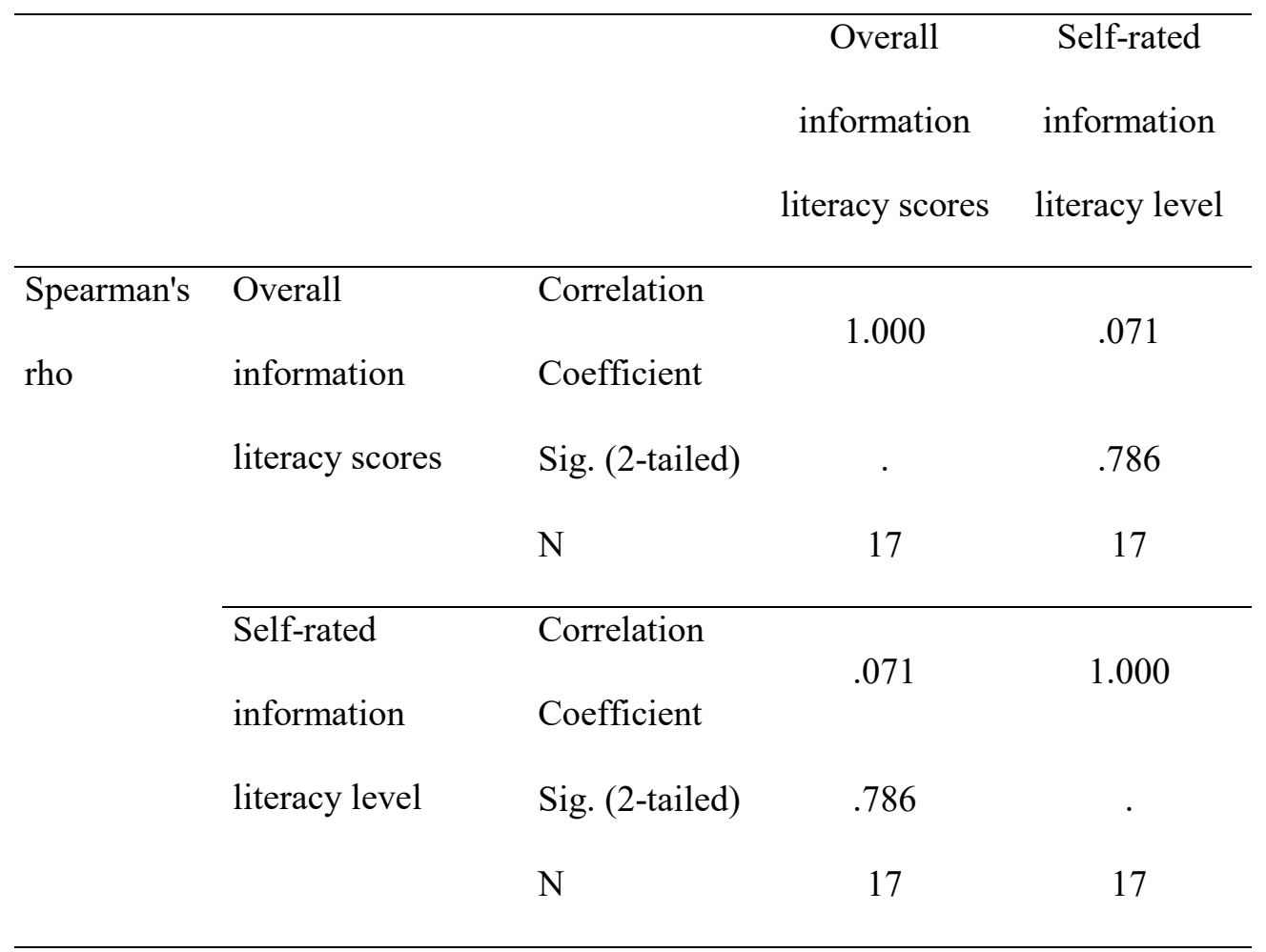


Table 4

Correlation of hearing/reading about IL and IL scores

\begin{tabular}{lccc}
\hline & & & Asymp. Sig. \\
& Value & df & (2-sided) \\
\hline Pearson Chi-Square & $8.972^{\mathrm{a}}$ & 8 & .345 \\
Likelihood Ratio & 9.252 & 8 & .321 \\
Linear-by-Linear & 1.114 & 1 & .291 \\
Association & & & \\
N of Valid Cases & 17 & & \\
\hline
\end{tabular}

a. 18 cells $(100.0 \%)$ have expected count less than 5 . The minimum expected count is .18 . 


\section{Figures caption}

Fig. 1: Expanded AASL's information literacy model

Fig. 2: Overall information literacy scores

Fig. 3: Self-rated information literacy level 
Figures

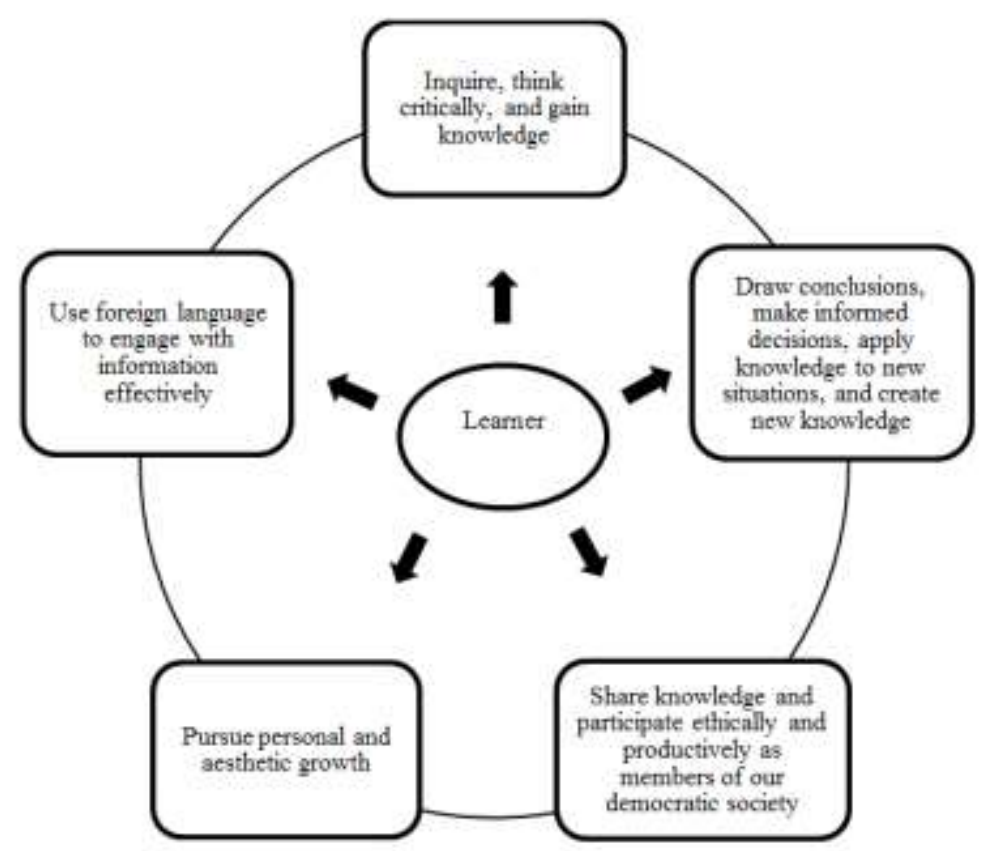

Fig. 1: Expanded AASL's information literacy model 


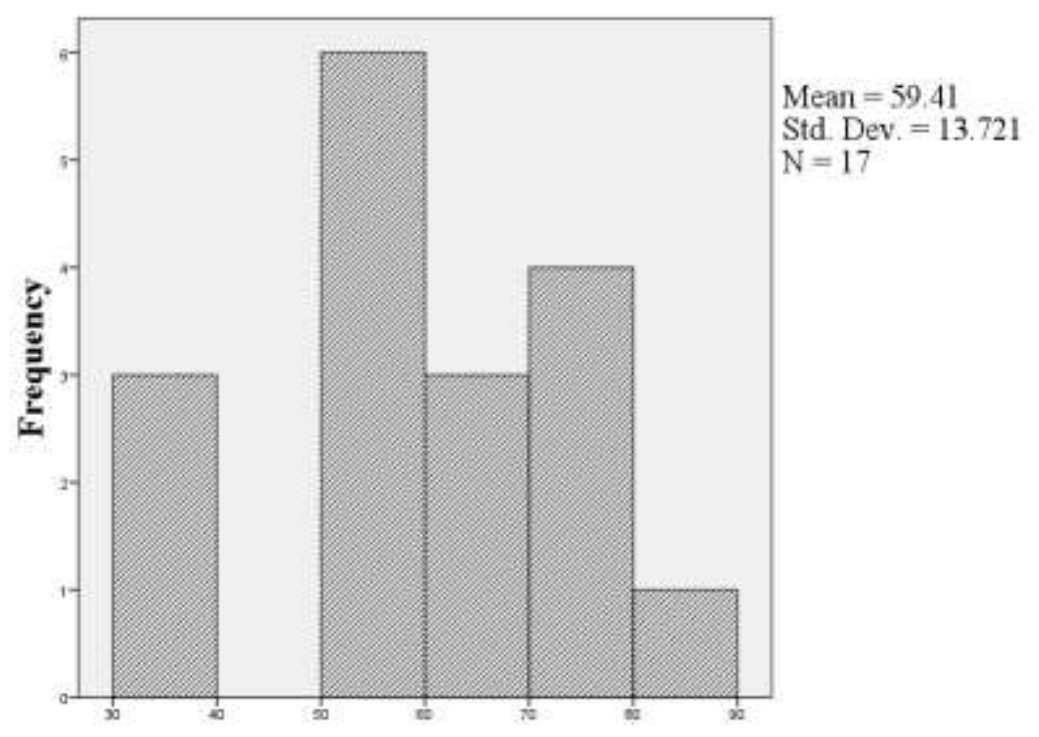

Fig. 2: Overall information literacy scores 


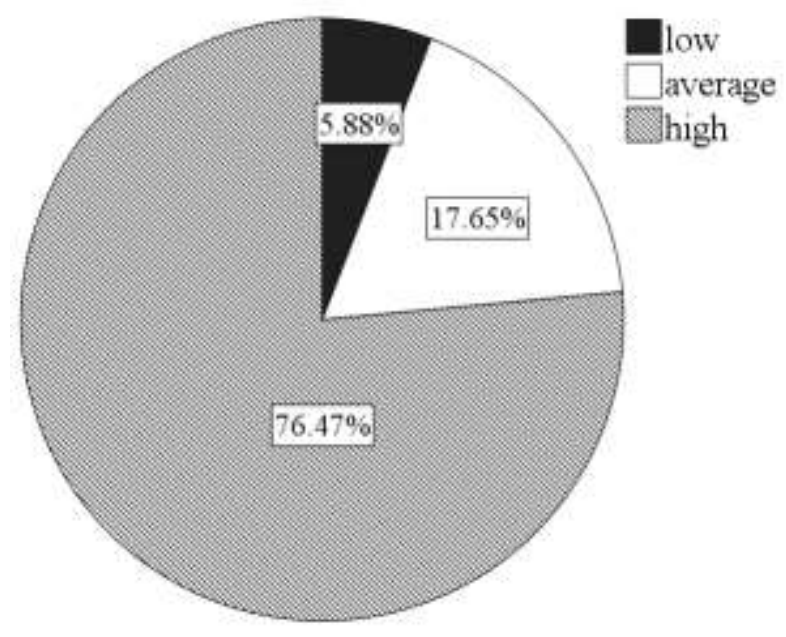

Fig. 3: Self-rated information literacy level 